\section{AB0878 COMPARISON OF CLINICAL FEATURES IN PATIENTS WITH PSORIATIC ARTHRITIS AND PATIENTS WITH SPONDYLOARTHRITIS WITH INFLAMMATORY BOWEL DISEASE}

M. Uematsu ${ }^{1}, 2$, K. Inuii ${ }^{1}$, T. Okano ${ }^{1}$, Y. Yamada ${ }^{1}$, K. Mandai $^{1}$, Y. Sugikoka ${ }^{3}$, K. Mamoto ${ }^{1}$, T. Koike $^{3,4}$, H. Nakamura'. ${ }^{1}$ Department of Orhopedic surgery, Osaka City University Graduate School of Medicine: ${ }^{2}$ Department of Orhopedic surgery, Higashisumiyoshi morimoto hospital; ${ }^{3}$ Center for Senile Degenerative Disorders $(C S D D)$, Osaka City University Graduate School of Medicine, Osaka; ${ }^{4}$ Search Institute for Bone and Arthritis Disease (SINBAD), Shirahama Foundation for Health and Welfare, Wakayama, Japan

Background: Spondyloarthritis $(\mathrm{SpA})$ is one of the representative comorbidity in patients with psoriasis (PsO) and inflammatory bowel disease (IBD) disease. However, the difference of clinical features between SpA due to PsO (PsA) and SpA due to IBD (IBD-SpA) are unclear.

Objectives: The purpose of this study is to compare the clinical features between patients with PsA and IBD-SpA.

Methods: Overall, 192 patients with $\mathrm{PsO}$ and 37 patients with IBD were included in this cross-sectional study. Clinical classification of PsA and IBD-SpA were performed according to the CASPAR ${ }^{1}$ criteria and ASAS criteria. ${ }^{2}$ Disease activity (DAS28-CRP), C-reactive protein (CRP), matrix metalloproteinase-3 (MMP-3), anti-cyclic citrullinated peptide antibody (ACPA), rheumatoid factor (RF), biologic disease modifying anti-rheumatic drugs (bDMARDs) use, and proportion of peripheral and axial disease were evaluated in patients with PsA and IBD-SpA.

Results: In this analysis, 74 patients were classified as PsA, 65 patients as PsO, 17 patients as IBD-SpA and 20 patients as IBD. The mean age was $56.0 \pm 14.7$ years in PsA, $44.7 \pm 10.9$ years in IBD-SpA $(p=0.003)$. The mean BMI was 24.2 $\pm 4.5 \mathrm{~kg} / \mathrm{m}^{2}$ in $\mathrm{PsA}, 23.3 \pm 7.2 \mathrm{~kg} / \mathrm{m}^{2}$ in IBD-SpA $(\mathrm{p}=0.18)$. DAS28-CRP was 3.26 \pm 1.26 in PsA, 4.02 \pm 1.5 in IBD-SpA $(p=0.12)$. Axial SpA was observed in $4(5.4 \%)$ in PsA, 5 (29.4\%) in IBD-SpA ( $p=0.01)$. Biologics were used in 29 (39.2\%) patients in PsA, 13 (76.5\%) patients in IBD-SpA ( $p=0.007)$. Proportion of seropositive ratio was not significant in this two groups.

Abstract AB0878 - Table 1. Characteristics in patients with PsO, PsA, IBD and IBD-SpA.

\begin{tabular}{lccccc}
\hline & PsA $(n=74)$ & PsO $(n=65)$ & IBD-SpA $(n=17)$ & IBD $(n=20)$ & $P$ value $^{*}$ \\
\hline Age, years & $56.0 \pm 14.7$ & $60.2 \pm 14.0$ & $44.7 \pm 10.9$ & $45.0 \pm 12.8$ & 0.003 \\
Female, $\mathrm{n}(\%)$ & $36(48.6)$ & $29(44.6)$ & $8(47.0)$ & $16(80.0)$ & 1.0 \\
Height, m & $1.63 \pm 0.09$ & $1.61 \pm 0.09$ & $1.65 \pm 0.07$ & $1.59 \pm 0.06$ & 0.43 \\
Body weight, kg & $65.3 \pm 16.8$ & $61.7 \pm 13.1$ & $64.7 \pm 24.8$ & $51.8 \pm 12.2$ & 0.34 \\
BMI, kg/m ${ }^{2}$ & $24.2 \pm 4.5$ & $23.7 \pm 3.9$ & $23.3 \pm 7.2$ & $20.4 \pm 3.9$ & 0.18 \\
DAS28-CRP & $3.26 \pm 1.26$ & $1.91 \pm 0.9$ & $4.02 \pm 1.5$ & $2.53 \pm 0.8$ & 0.12 \\
CRP, mg/dl & $1.32 \pm 3.3$ & $0.32 \pm 0.6$ & $1.0 \pm 1.1$ & $0.78 \pm 2.4$ & 0.12 \\
MMP-3, ng/ml & $99.9 \pm 95.3$ & & $92.1 \pm 59.0$ & & 0.90 \\
ACPA positive, $\mathrm{n}(\%)$ & $6(8.1)$ & & $0(0)$ & & 0.59 \\
RF positive, $\mathrm{n}(\%)$ & $7(9.5)$ & & $1(5.9)$ & & 1 \\
\hline
\end{tabular}

*Mann-Whitney U-test and Fisher's exact test were performed in comparison with PsA and IBD-SpA.

Abstract AB0878 - Table 2. Prevalence of axial SpA and peripheral SpA in patients with PsA and IBD-SpA.

\begin{tabular}{lccr}
\hline & PsA $(n=74)$ & IBD-SpA $(n=17)$ & P value \\
\hline Axial SpA, $n(\%)$ & $4(5.4)$ & $5(29.4)$ & 0.01 \\
Peripheral SpA, $n(\%)$ & $70(94.6)$ & $12(70.6)$ & \\
\hline
\end{tabular}

Conclusions: The clinical features between patients with PsA and IBD-SpA were compared. The patient with IBD-SpA was younger than patient with PsA and the prevalence of axial disease was more frequent in IBD-SpA.

\section{REFERENCES}

[1] Taylor W, Gladman D, Helliwell P, et al. Classification criteria for psoriatic arthritis: development of new criteria from a large international study. Arthritis Rheum. 2006;54:2665-73.

[2] Rudwaleit M, van der Heijde D, Landewé R, et al. The Assessment of SpondyloArthritis International Society classification criteria for peripheral spondyloarthritis and for spondyloarthritis in general. Ann Rheum Dis. 2011;70:25-31.

Acknowledgements: We wish to thank Tomoko Nakatsuka for clinical assistant. Disclosure of Interest: None declared DOI: 10.1136/annrheumdis-2018-eular.4473

\section{$\mathrm{AB} 0879$ \\ FIBROMYALGIA IN PATIENTS WITH ANKYLOSING SPONDYLITIS: PREVALENCE AND RELATIONSHIP WITH DISEASE ACTIVITY}

M. Sahli, O. Saidane, I. Mahmoud, A. Ben Tekaya, R. Tekaya, L. Abdelmoula. Rheumatology, Charles Nicolle Hospital, Tunis, Tunisia

Background: Spondyloarthritis (SpA) is an inflammatory rheumatic disease, characterised by spinal involvement, peripheral arthritis, or enthesitis with marked pain, stiffness, and fatigue. Fibromyalgia (FM) may be associated with $\mathrm{SpA}$, and shares some common symptoms.

Objectives: We aimed to estimate the prevalence of FM in SpA and its influence on the assessment of SpA disease activity.

Methods: This single-centre cross-sectional study included consecutive patients with SpA according to the Assessment of SpondyloArthritis International Society criteria. FM was diagnosed according to the 2010 American College of Rheumatology criteria. All patients underwent clinical evaluation of disease activity using the Bath Ankylosing Spondylitis Disease Activity Index (BASDAI), the Bath Ankylosing Spondylitis Functional Index (BASFI) and the Ankylosing Spondylitis Disease Activity Score (ASDAS) and then compared in patients with and without FM. Results: The study included 100 patients with SpA, 67 males and 33 females with a median age of 44.65 years. The prevalence of fibromyalgia was $20 \%$. Patients fulfilling the criteria of FM presented a higher total BASDAI $(5.86( \pm 1.97)$ vs. $3.15( \pm 1.99), \mathrm{p}<0.01)$, higher ASDAS-CRP $(3.43( \pm 1.13)$ vs. $2.41( \pm 1)$ $\mathrm{p}<0.01)$, higher ASDAS-VS $(3.5( \pm 1.12)$ vs. $2.53( \pm 1.02), \mathrm{p}<0.01)$ and poorer function scores (BASFI) $(6.76( \pm 1.97)$ vs. $3.8( \pm 2.59), p<0.01)$.

Conclusions: $\mathrm{FM}$ is a frequent comorbidity in patients with $\mathrm{SpA}$. In patients with SpA-FM, disease activity may be overestimated and this overestimation could lead to inappropriate treatment escalation.

\section{REFERENCES:}

[1] Azevedo VF, Paiva E dos S, Felippe LRH, Moreira RA. Occurrence offibromyalgia in patients with ankylosing spondylitis. Rev Bras Reumatol.2010;50:646-50.

[2] Salaffi F, De Angelis R, Carotti M, Gutierrez M, Sarzi-Puttini P, Atzeni F. Fibromyalgia in patients with axial spondyloarthritis: epidemiological profileand effect on measures of disease activity. Rheumatol Int 2014;34:1103-10.

Disclosure of Interest: None declared

DOI: 10.1136/annrheumdis-2018-eular.5992

\section{AB0880 THE OBJECTIVE AUTOMATED MEASUREMENT OF FLUORESCENCE-SIGNAL INTENSITIES IN FLUORESCENCE-OPTICAL IMAGING TECHNIQUE DISCRIMINATES BETWEEN DISEASE ACTIVITY AND ITS RESPONSE IN ANTITNF TREATED PSORIATIC ARTHRITIS PATIENTS - AN INTERIMS ANALYSIS OF THE XPLORE-STUDY}

M. Köhm ${ }^{1,2}$, S. Ohrndorf ${ }^{3}$, T. Rossmanith ${ }^{2}$, A. Foldenauer ${ }^{2}$, U. Henkemeier ${ }^{4}$, G. Schmittat ${ }^{5}$, J. Berger ${ }^{6}, H$. Burkhardt ${ }^{1,2}$, F. Behrens ${ }^{1,2}$, on behalf of The XploreStudy Group. ${ }^{1}$ Rheumatology, Goethe-University FrankfurtMain; ${ }^{2}$ Clinical Research, Fraunhofer IME TMP, FrankurtMain; ${ }^{3}$ Rheumatology and Immunology, Universitätsmedizin Charité, Berlin; ${ }^{4} \mathrm{CIRI}$, Goethe-University Frankfurt/Main; ${ }^{5}$ Rheumatology and Immunology, Universitätsmedizin Charité, FrankurtMain; ${ }^{6}$ Xiralite $\mathrm{GmbH}$, Berlin, Germany

Background: Psoriatic arthritis (PsA) is a chronic inflammatory disorder combin ing joint and musculoskeletal inflammation. AntiTNF-therapy is induced after failure of NSAID and DMARD treatment. Up to $30 \%-40 \%$ of the patients are primary not responding adequately to the induced biological therapy. In daily practice response is calculated by improvement of disease activity measured by clinical examination and calculated using composite indices. Feasible and robust biomarkers for prediction of response are missing

Methods: Fluorescence optical imaging (FOI) is used as method for detection of changes in microvascularisation of the hands as potential marker for inflammation. ICG is injected as fluorescence agent, that is than stimulated by light and recorded by a specific camera system. An automated computer-based reading of the disease activity (DACT) is used as an objective method to display overall fluorescence-signals and their intensities. In a prospective multicentre study, the value of FOI in measurement of disease activity and its predictive value to discriminate responders in newly treated PsA patients is currently investigated in the XPLORE-study. This interim analysis investigates the value of baseline (BL) DACT to discriminate between responders (at least low disease activity (LDA) with DAS28 $\leq 3.2$ ) and non-responders compared to standard clinical disease measurements (SJC, TJC, DAS28) over the 52 weeks observational period. 
Results: Data from 23 patients were analysed during the 52 weeks observational period. Mean age was 54.7 years, $60 \%$ of the patients were female. Mean DAS28 at baseline was 4.26, mean BSA 9\%, whereas mean values for SJC were 5.9 and TJC 11.4 using 66/68 joint count. All patients were negative for ACPA and rheumatoid factor

ROC analysis revealed that a DACT cut-off of 4.55 at baseline, indicating moderate expression of fluorescence intensities in context of disease activity, shows a predictive quality to LDA achievement at W52 with $80 \%$ specificity, $78 \%$ sensitivity and likelihood ratios of 3.89 (LQ+) and 0.28 (LQ-). The corresponding AUC value is $0.717(95 \% \mathrm{Cl}=[0.393,1] ; \mathrm{p}=0.146)$. Compared to clinical disease measurements such as baseline DAS28, TJC or SJC, the DACT at BL is more discriminative to identify patients who attain LDA at W52.

Conclusions: This interim analysis of the XPLORE study shows promising data for the use of FOI as possible imaging biomarker for disease activity measure and prediction of response in PSA-patients newly treated with antiTNF-therapy: Baseline values evaluated using the automated computer-based reading of the fluorescence intensities with a cut-off of 4.55 are predictive for later achievement of DAS28 low-disease activity or remission within the treatment course. Data will be verified in a larger cohort of the XPLORE study.

Disclosure of Interest: M. Köhm Grant/research support from: Pfizer Germany, S. Ohrndorf: None declared, T. Rossmanith: None declared, A. Foldenauer: None declared, U. Henkemeier: None declared, G. Schmittat: None declared, J. Berger Employee of: Xiralit GmbH, H. Burkhardt Grant/research support from: Pfizer Germany, F. Behrens Grant/research support from: Pfizer Germany

DOI: 10.1136/annrheumdis-2018-eular.6764

\section{AB0881 ASSOCIATION OF RS12218 POLYMORPHISM IN SAA1GENE WITH LUMBAR SPINE SYNDESMOPHYTES IN THE RUSSIAN ANKYLOSING SPONDYLITISPOPULATION. A PILOT STUDY}

M. Krylov ${ }^{1}$, S. Erdes ${ }^{1}$, A. Starkova ${ }^{1}$, E. Samarkina ${ }^{1}$, I. Guseva ${ }^{1}$, N. Konovalova ${ }^{2}$ D. Varlamov ${ }^{2} .{ }^{1}$ V.A. Nasonova Research Institute of Rheumatology, ${ }^{2}$ All-Russian Research Institute of Agricultural Biotechnology, Moscow, Russian Federation

Background: Ankylosing spondylitis (AS) is a chronic inflammatory disease from the group of spondyloarthritis (SPa). Earlier studies showed a correlation between SAA1 gene polymorphism, encoding serum amyloid $A$, and the development of secondary AA-amyloidosis in familial Mediterranean fever and rheumatoid arthritis in Caucasian and Asian populations. The Moriguchi et al (2005) study showed that the $-13 \mathrm{~T} / \mathrm{C}$ polymorphism in the gene 5'-flanking region ( $r$ 12218) is a better marker of AA-amyloidosis than mapping of polymorphisms in SAA1 exon 3 (SAA1.1 and SAA1 1.3). Data on rs12218 polymorphism contribution into predisposition to AS and its clinical phenotypes are very scarce. One of the clinical phenotypes, determining the severity of spine damage, is associated with presence of syndesmofytes (SM) in the lumbar (SMI), thoracic (SMt) and cervical (SMc) spine, confirmed by $\mathrm{x}$-ray data.

Objectives: To study potential associations of rs12218 polymorphism in SAA1 gene with AS and phenotypes of radiographic progression, with the presence of SMI, SMt and SMc, and correlation with BASDAI, BASFI and ASAS indices.

Methods: rs 12218 polymorphism was studied in 112 subjects: 47 AS patients (37 males and 10 females, mean age 40y, mean disease duration 213 weeks, mean age at onset 22y, positive for HLA-B27), and 65 healthy volunteers (controls). Genotyping was performed using allele-specific polymerase chain reaction in real time (PCR-RT).

Results: The Pearson Correlation analysis showed negative correlation between rs12218 polymorphism and presence of SMI, as well as BASDAI, BASFI scores $(r=-0.39, r=-0.35$ and $r=-0.36, p=0.006, p=0.017, p=0.014$, respectively). There were no correlations between rs12218 and pts' age, AS duration and pts' age at AS onset. There were similar rs12218 allele distribution rates between AS patients and the controls. rs $12218 \mathrm{C}$ allele rates were significantly higher in SMl group $(n=23)$ compared to subjects without SMl $(n=24)[50.0 \%$ vs. $15.2 \%$, $\mathrm{p}=0.001]$. No association was established between $\mathrm{C}$ allele and presence of SM in other parts of the spine. A correlation between BASDAI and BASFI scores and SAA1 gene rs12218 polymorphism was established. Mean BASDAI score was significantly higher in carriers of TC and CC genotypes compared to carriers of TT genotype $(5.6 \pm 1.3$ vs. $3.9 \pm 2.3, p=0.004)$. The mean BASFI scores in carriers of the respective genotypes were $(6.1 \pm 2.3$ vs $4.1 \pm 2.8, p=0.012)$. No significant correlation was found between rs12218genotypes and mean ASDAS score values. Conclusions: Therefore, this pilot study is the first to show the possible participation of rs12218 polymorphism in SAA1 gene in AS pathogenesis in Russian population. We suggest that $C$ allele may be is a risk factor predisposing to SMI [OR $5,1495 \% \mathrm{Cl}(1.75-16.17), \mathrm{p}=0.001]$. The data obtained on a limited sample of patients require further validation on larger samples of patients involving different population groups.

Disclosure of Interest: None declared

DOI: 10.1136/annrheumdis-2018-eular.2466

\section{AB0882 \\ ACHILLES ENTHESITIS IN THE PATIENTS WITH SPONDYLOARTHRITIS: RELATIONSHIP WITH MUSCLE STRENGTH, ACTIVITIES OF DAILY LIVING AND QUALITY OF LIFE}

Ö. Kuru, B. Farisoğulları, G. Alayli, A. Bilgici, D. Durmuş. Physical Medicine and Rehabilitation, Ondokuz Mayıs University Medical Faculty, Samsun, Turkey

Background: Enthesitis is a central feature of spondyloarthritis (SpA). In SpA the entheses of the lower extremities are more commonly involved than those of the upper limbs, and the heel is the most frequent site. Investigation of peripheral enthesitis in SpA is based on clinical findings and/or imaging findings. The involvement of Achilles tendon may lead to pain, movement restrictions, decrease in muscle strength, and eventually a diminished quality of life (QoL).

Objectives: In the present study, we aimed to evaluate clinical enthesopathy and relation with ankle muscle strength, activities of daily living (ADLs) and foot and ankle related QoL in the patients with $\mathrm{SpA}$.

Methods: Sixty SpA patients fulfilling the Assessment of SpondyloArthritis International Society (ASAS) classification criteria for SpA (M/F=39/21) $(35.61 \pm 9.85$ years) and 50 healthy controls $(M / F=32 / 18)(35.40 \pm 10.62$ years) were enrolled in the study. Clinical enthesopathy was defined by the presence of at least one of the spontaneous pain, tenderness elicited by pressure, mobilisation and contraction against resistance of the corresponding tendons and local swelling of the enthesis. Pain by visual analogue scale (VAS), disease activity by Bath Ankylosing Spondylitis Disease Activity Index (BASDAI), functional capacity by Bath Ankylosing Spondylitis Functional Index (BASFI), enthesitis severity by SPARCC index was assessed in the patients. Isokinetic measurements of ankle dorsiflexion and plantarflexion were performed by the isokinetic dynamometer. The participants were tested at $30^{\circ}$ and $120^{\circ} / \mathrm{sec}$ angular velocities. Pain, other symptoms (stiffness, swelling, range of motion), ADLs, sport and recreational activities, and foot and ankle-related QoL were evaluated by the Foot and Ankle Outcome Score (FAOS) in which higher scores indicate lesser problems and/or functional limitations.

Results: There was no significant difference between the patients and controls regarding age, sex, and body mass index. Clinical enthesopathy was detected in $36.7 \%$ of the SpA patients. Although ankle plantarflexion and dorsiflexion muscle strength in all angular velocities were lower in the SpA patients, the difference did not reach statistical significance $(p>0.05)$. All of the FAOS subscales were found to be significantly lower in the patients with SpA than in the controls $(p<0.001)$ When the SpA patients were divided into two groups as with clinical enthesopathy $(n=22)$ and without clinical enthesopathy $(n=38)$, there were significant differences between the groups regarding VAS pain, BASDAI, BASFI and SPARCC scores whereas there was no significant difference in muscle strength. Also, all FAOS subscale scores were significantly lower in the patients with clinical enthesopathy. Additionally, in the patients with $\mathrm{SpA}$, while there were negative correlations between VAS pain, BASDAI, BASFI, SPARCC and FAOS subscale scores, there was a positive correlation between ankle muscle strength and FAOS scores $(\mathrm{p}<0.05)$.

Conclusions: We found that all the FAOS subscale scores were lower in the SpA patients and they were correlated with clinical findings. The results of our study indicate that even though there was not a significant decrease in the muscle strength, ADLs, sport and recreation activities, foot-related QoL are poorly affected in the SpA patients with Achill enthesitis.

Disclosure of Interest: None declared

DOI: 10.1136/annrheumdis-2018-eular.6361

\section{$\mathrm{AB} 0883$ \\ ASSESSMENT OF EARLY MYOCARDIAL DYSFUNCTION USING SPECKLE TRACKING ECHOCARDIOGRAPHY IN PATIENTS WITH RADIOGRAPHIC AND NONRADIOGRAPHIC AXIAL SPONDYLOARTHRITIS}

V. Emren ${ }^{1}, \underline{\text { O. Gercik }}{ }^{2}$, E. Ozdemir ${ }^{1}$, D. Solmaz ${ }^{2}$, S. Gucenmez ${ }^{2}$, N. Eren ${ }^{1}$,

M. Tokac ${ }^{1}$, G. Kabadayi ${ }^{2}$, S. Akar ${ }^{2}{ }^{1}$ Cardiology; ${ }^{2}$ Rheumatology, Izmir Katip Celebi University School of Medicine, Izmir, Turkey

Background: Axial spondyloarthritis (axSpA) is a chronic inflammatory disease that mainly affects axial skeleton. Although some differences like sex and objective signs of inflammation were described between these two subgroups, overall disease burden was found to be similar in radiographic ( $r$-) and non-radiographic (nr-) axSPA patients. The association of chronic inflammation with cardiac dys function was well documented in many inflammatory rheumatic diseases. However it was not assessed in the subgroups of axSpA patients. Advanced twodimensional (2D) speckle tracking echocardiographic analysis is more sensitive and accurate method of early detection of myocardial dysfunction than the conventional 2D transthoracic echocardiography (TTE).

Objectives: To evaluate the left ventricular function by using speckle tracking echocardiography in patients with both $r$ - and nr-axSpA.

Methods: In total 64 patients with r-axSpA (70\% male) and age- and sexmatched 27 patients with nr-axSpA (63\% male) and 30 healthy control subjects 